\title{
Challenges In Cross-Cultural Business Education
}

\author{
Ms. Alli Nathan, PhD, Providence College, USA \\ Ms. Margaret Ruggieri, MST, CPA, Providence College, USA
}

\begin{abstract}
One of the most important and lasting legacies of the $20^{\text {th }}$ century is globalization and the increased integration among countries and economies leading to more interactions among the peoples of different cultures. This effect has also percolated into the business environment and into the realm of business education. We have seen the internationalization of the business curriculum, the creation of more study abroad programs for students, and the increased efforts towards exchange programs for educators. Conflicts in cross-cultural learning environments have been examined primarily from the perspective of the student, with limited research on the experiences of the teacher. We use Hofstede's (1980) cultural dimensions to identify the characteristics of teacher-student pairs from different cultures, explore the potential conflicts that may be created, and offer suggestions for developing strategies to be a globally competent teacher.
\end{abstract}

Keywords: Business education; off-shore teaching; cultural dimensions; cross-cultural conflicts; global competent teacher

\section{PRELUDE}

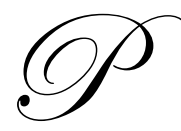

rofessor $\mathrm{X}$ is a quintessential American accounting academic, having done her graduate and undergraduate degrees in accounting at prestigious business schools in New England. She started her career as an accounting professional working with both audit and tax clients in one of the big 4 public accounting firms, and earning her CPA. However, her passion for teaching and learning eventually led to her becoming a professor of accounting also at a leading, liberal arts school in New England. She is an excellent teacher having taught courses throughout the accounting curriculum. Her teaching style is unlike the purely teacher centered lecture style she experienced as a student. Incorporating a more cooperative and interactive learning environment in the classroom she integrates the Socratic method along with the use of technology and various group activities to provide the students with a variety of effective learning strategies that better align with the learning styles of the millennial student in today's classroom. The students are no longer passive recipients of information but rather are active learners who are developing and expanding their communication, intellectual and interpersonal skills.

In 2006, she was offered an opportunity to teach in a specialized business program in the Middle East to a small group of Muslim, female students. Her only preparation for this off-shore teaching assignment was a one hour conversation with the organizer of the program, who emphasized the cultural differences between America and the Arab world, but provided little guidance on dealing with such issues. She was only marginally prepared for the social and cultural differences she experienced during her three week assignment. She did an excellent job of teaching American accounting albeit with key Arabic adaptations, as well as managing the art of doing it in a different cultural setting, over an intense three week period, which also incidentally coincided with the Arab tradition of fasting during the Ramadan. She had to adapt to the culture and customs of students - such as holding classes between $1 \mathrm{pm}$ and $4 \mathrm{pm}$ to accommodate the late night life style of the students. The cultural importance of the success of the group versus individual success was foreign to her and she became sensitive to this issue. For example, the students considered it acceptable to share answers with one another even on individual assignments. The students always addressed her as "professor" and never challenged her authority or knowledge. While she is 
extremely proud of what she accomplished with her students, she feels that pre-departure preparation in terms of cultural dimensions and their impact on learning styles would have helped her adopt her teaching style to be more effective.

\section{INTRODUCTION}

"As teacher/student interaction is such an archetypal human phenomenon so deeply rooted in the culture of a society, cross-cultural learning situations are fundamentally problematic for both parties." - Hofstede (1986)

The experience described above serves to illustrate the sentiments of Hofstede (1986), whose seminal work on culture and its consequences (1980, 1986, and 2001) - despite its many critics - serves as the standard for research on cross-cultural issues. While cross-cultural teaching and learning may be "fundamentally problematic" (Hofstede, 1986) for the academic and the student, we believe that weaving cultural dimensions into teaching and learning will provide insights for developing "globally competent teachers" (Badley, 2000).

One of the most important and lasting legacies of the $20^{\text {th }}$ century is globalization and the increased integration among countries and economies leading to more interactions among the peoples of different cultures. This effect has also percolated into the business environment as reflected in the increasing presence and influence of multinational corporations, and the need to deal with people and personnel in different cultures. We also see the impact on business education - internationalization of the business curriculum, creation of more study abroad programs for students, and increased efforts towards exchange programs for educators. Deans and administrators encourage such cross-cultural exchanges, and are increasingly interested in understanding the issues and implications of sending students and faculty for overseas learning and teaching.

Indeed, organizations such as the Institute of International Education (IIE) and Council for International Educational Exchange (CIEE) have been established in the United States of America to facilitate the study abroad experiences of students, and conduct research on related issues, such as understanding learning styles and experiences across cultures, expatriation and repatriation of students, etc. Most major universities around the world have offices headed by administrators at the level of Deans to encourage student exchanges around the world.

At the same time, the number of overseas assignments of educators, in the form of both short-term (a few weeks, often referred to as off-shore teaching) and long-term (a few months up to a year, traditionally known as international teaching) has also increased. However, while many professors do indeed go overseas to teach in cross cultural environments, the facilities available to enhance their experiences are limited. And, there is only limited research on issues that are relevant to such educator experiences. But, there is evidence to indicate that more research is needed to understand these issues, given the need to develop globally competent teachers in a world that is integrating at a much faster rate in the $21^{\text {st }}$ century.

The objective of this paper is to analyze the limited information and research on off- shore teaching experiences of educators, and to add to the literature by extending the framework that links cultural differences to learning and teaching, when the student and the educator come from different cultural backgrounds. We expect our conclusions and recommendations to enhance and benefit the educators' off-shore teaching experiences, as well as the learning experiences of the foreign students.

We provide a brief summary of the limited literature dealing with cultural dimensions and cross-cultural education in Section 2 and present our key hypotheses in this regard. This is followed by a description of Hofstede's (1980) cultural dimensions in Section 3. Section 4 delineates the cultural conflicts that may arise in situations when the teacher and the student are from different cultures, and provides suggestions for resolving the conflicts, in order to create effective learning environments. Our conclusions and recommendations for successful cross-cultural teaching, along with the limitations of our research and suggestions for future research are discussed in Section 5. 


\section{LITERATURE REVIEW - HOFSTEDE'S CULTURAL DIMENSIONS AND CROSS-CULTURAL EDUCATION}

Hofstede (1991) describes culture as the "collective programming of the mind which distinguishes the members of one group or category of people from another". Hofstede's $(1980,2001)$ works on cultural dimensions provide the framework for understanding the cultural differences among peoples of different nations. His seminal work on cultural differences identifies four dimensions of culture - Power Distance, Uncertainty Avoidance, Individualism/Collectivism, and Masculinity/Feminism - based on the analysis of employees of a multinational corporation with operations in 40 countries (Hofstede 1980). Hofstede later updated his study to include analysis of IBM employees in 50 countries and 3 regions and defined a fifth cultural dimension, related to the long term and short term orientations of different cultures (Hofstede 2001). However, due to the differences in methodology of the later study, and the limited sample size, we focus on the original four dimensions.

These dimensions can be applied to teachers and students in cross-cultural situations to identify characteristics of student-teacher interactions, and cultural differences in teaching and learning (Hofstede, 1986). While these dimensions have been applied to understand the learning methods of students from different cultures (Richardson 1994, Richards and Ross 2004, and Manikutty et al 2007), there are hardly any studies (at least, to our knowledge) that analyze the teaching methods of the educator, and none dealing with the issues and the conflicts that arise in situation when the student and the teacher come from different cultures. In such situations, issues such as the social position of the teacher, the curriculum, the cognitive abilities of students, the expected teacher/student interactions can either enhance or diminish the learning experience of the student and the teaching experience of the teacher.

Gibb (1996) proposes a model of teaching that is flexible, holistic, culturally sensitive, and enterprising as being more appropriate in today's globalized, multi-cultural, student-centered learning environments. But, it is also possible that the traditional teacher-centered style of an "expert" - the teacher - passing on the knowledge to a largely passive student audience, is more relevant in some situations. Ramburuth (2000) suggests that educators need to take into consideration cultural differences of students in designing the curriculum as well as in delivering it.

Badley (2000) and Hall (2007), on the other hand focus on the need to develop globally competent academics, and the benefits of professors teaching abroad. Badley (2000) identifies the following as the characteristics of a globally competent educator - academic competence, operational competence, a democratic approach and an ethnographic mindset. These are regarded as being fundamental for success in cross-cultural education. Most academics excel in both academic (content) and operational (delivery) competence; but, in an international context the educators need to add democratic and ethnographic dimensions to their teaching paradigm. This will provide the flexibility to embrace the cultural uniqueness of each student group and assume appropriate teaching methods to excel in a particular cultural environment.

Hall (2007), on the other hand, discusses the transformative and eye-opening nature of the overseas teaching experience, leading to lessons that would otherwise never be learnt. It increases one's self-awareness, and enhances one's teaching at the home institutions. Some of these lessons are obviously driven by the cross-cultural nature of the teaching and the learning experience. While cross-cultural teaching and learning may be fundamentally problematic for the academic and the student, we believe that being aware of cultural dimensions / characteristics of the teacher and the student will provide insights for developing globally-competent teachers.

Hofstede (1986) states that "it is possible that in order to be effective as trainers abroad teachers have to adopt methods which at home they have learned to consider as outmoded or impopular - usually much more structure than they were accustomed to". We believe that cross-cultural education must integrate the cultural dimensions of the global teacher with the cultural dimensions of the local student. This is becoming increasingly relevant and important as both students and educators cross borders to enhance their experiences.

We explore the links between cultural dimensions and pedagogical issues, in an effort to provide an integrated framework, as illustrated in Figure 1, which depicts the interface between teachers and students in a crosscultural environment. Educators teaching across cultures can use this paradigm to redesign their pedagogy to meet the needs of their overseas students. 
Figure 1

Integration of Culture and Education \& Interface between Students \& Teachers

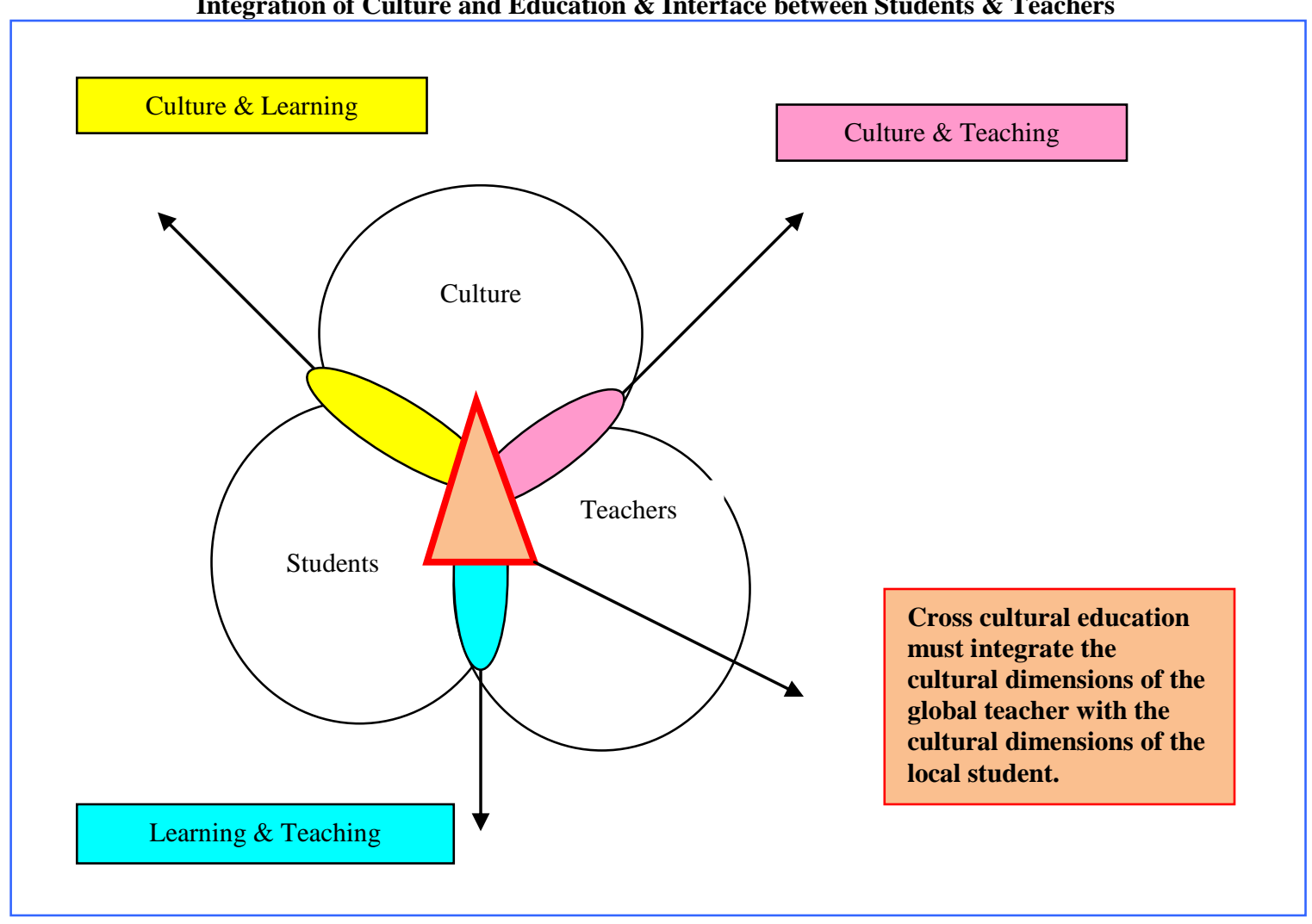

We hypothesize that culture and its dimensions have an influence on the students, the teachers, and the student / teacher interactions, and identify potential conflicts that arise in cross-cultural situations. We use this integrated framework in an effort to provide tools for developing globally competent business educators. We also use the cultural dimensions, identified by Hofstede $(1980,1986)$, to understand how cross-cultural differences influence the expectations of students in off-shore locations, and how differences in student characteristics across culture lead to shifts in the teaching paradigms of teachers with off-shore teaching experiences. We expect to provide suggestions for developing globally competent teachers in a world that is increasingly becoming an integrated one. This is fundamental to teaching excellence in a dynamic educational environment and providing local and global students with an exceptional learning experience.

\section{HOFSTEDE'S CULTURAL DIMENSIONS}

Hofstede's classical framework of cultural dimensions includes the following four attributes as characterizing individuals in any society/country - power distance, uncertainty avoidance, individualism/collectivism and masculinity/femininity. These cultural dimensions can be applied to students and teachers in cross-cultural situations to identify fundamental differences in learning and teaching (Hofstede, 1986). The differences also may lead to conflicts in traditional student-teacher interactions, which may result in less than optimal learning and teaching experiences. Here we describe the basic tenets of the four dimensions before dealing with the potential conflicts that may arise.

In addition to characterizing the attributes of each dimension, Hofstede (1986) also developed an index for each dimension, for each country, for use in comparative analysis. Each index has a mean of 53, and a range as indicated below. A country index that is more/less than the mean is taken as an indicator that the country's overall culture is characterized by a high/low degree of that particular dimension/attribute. 


\section{Power Distance (Power Distance Index (PDI) Range: 11 to 104)}

"All societies are unequal, but some are more unequal than others" (Hofstede, 1980). The power distance dimension considers the human inequality within a culture. It measures the extent to which the less powerful in the culture accept the disparity of their societal relationship with those in power. With respect to the interrelationship of teacher and student, power distance is strong in a teacher centered classroom where the teacher is considered the authority and students are dependent upon the teacher. Conversely, the power distance dimension is weak in a student-centered environment, where teacher and student are considered equals. Spencer-Oatey (1997) reported on a comparative survey study on tutors and students in China (high PDI) and Great Britain (low PDI) about their mutual relationship. The Chinese students and tutors indicated a greater inequality in their relationship yet a closer bond than the respondents from Great Britain, with some linking the teacher-student relationship to a father-son relationship.

\section{Uncertainty Avoidance (Uncertainty Avoidance Index (UAI) Range: 5 to 95)}

Uncertainty avoidance relates to how a culture accepts and reacts to ambiguity. In a society that has a low tolerance for the unpredictability of the future, establishing a strict set of rules of conduct helps to control the outcome and reduce the apprehension caused by the continuous threat of the unknown. For example, in a culture with a high level of uncertainty avoidance, the teacher is assumed to have all the answers and the students desire a structured learning environment; whereas, in a low uncertainty avoidance culture, it is acceptable for the teacher to respond, "I don't know" and intellectual debate is supported. In Germany where there is a high uncertainty avoidance index, "German students are brought up in the belief that anything which is easy enough for them to understand is dubious and probably unscientific" (Stroebe, 1976). Likewise in France, where the uncertainty avoidance is strong, students typically will not engage in intellectual debate with their professor as it is viewed as personal disloyalty.

\section{Individualism vs. Collectivism (Individualism/Collectivism Index (ICI) Range: 8 to 112)}

Individualism and collectivism represent the opposite poles of the same cultural dimension. In an individualistic society, the focus is on "I" and on one's immediate family, whereas, in a collective society, "we" is paramount and absolute loyalty to the cohesive extended family/clan is expected (Hofstede, 2001). This relationship is reinforced in the classroom. In an individualistic culture, students are treated as individuals, with attention to individual accomplishments, and with the purpose of education being "learning to learn". Whereas, the emphasis in a highly collective classroom is on group harmony, "saving face" strategies, with no participation from individual students and with the goal of education being to learn "how to do", so that one can move up in status within their respective group. Furthermore, one's academic diploma represents a step towards economic wealth and self esteem in an individualist culture; whereas, the diploma represents improved social acceptance, such as a more attractive marriage partner in a highly collective society.

\section{Masculinity vs. Femininity (Masculinity/Femininity Index (MFI) Range: 6 to 91)}

The masculinity and femininity cultural dimension relates to society's view of the social role of the male gender. In other words, in a society that is considered to have a masculine cultural dimension, the male gender has a distinct role separate from the feminine role of nurturing and is expected to be assertive, competitive and selfconfident; whereas, in a feminine culture the male role overlaps with the female societal role of being sensitive and having personal rapport with others. With respect to the classroom environment, the foremost importance in a masculine culture is the teacher's intelligence and the student's academic success. Failure is considered catastrophic. Conversely, in a feminine society, emphasis is placed on the social skills of the students, with the teacher commending the weaker student vs. extolling the strong student. U. S. students who participated in a semester long program in the Netherlands were struck by the lack of concern for grades by the Dutch students who were satisfied with passing (Vunderink \& Hofstede, 1998). It is important to note that a country with a masculine cultural dimension like the United States can be a gender egalitarian society, whereas Japan and Korea are "feminine" societies in Hofstede's typology but could be male dominant. (Manikutty et al, 2007). 


\section{CONFLICTS IN CROSS-CULTURAL CLASSROOMS}

Teachers and students are part and parcel of the cultures in which they normally live, and their values, beliefs, attitudes, and characteristics are driven by the cultural dimensions that surround them, which in turn shape their teaching and learning strategies. While teaching and learning styles can vary from individual to individual, there is a collective set of assumptions and behaviors that tend to dominate a given classroom environment. For example, a teacher from Asia may expect to be treated with the utmost respect and be revered as the 'guru", while students in the US may find this foreign to their culture. Conflicts between the desired and desirable outcomes are created when a teacher from a foreign culture is faced with a group of students in their local environment.

Given the importance of student-centered teaching paradigms, the responsibility falls more on the shoulders of the educator to understand and identify the conflicts that can arise in such situations, and device strategies to ensure that the academic competence goes hand in hand with the operational competence of delivering to the students what is desired in a desirable style. This is vital for optimal interactions in the classroom. It may also be necessary and useful for the educator to briefly explore these issues with the students at the beginning of the session.

In this section we delve into the issue of cross-conflicts in classrooms by identifying potential conflicts between two teacher-student pairs: US teacher vs. Arabian student and US teacher vs. French student. Our discussion draws upon the four cultural dimensions and the national index values for each dimension advanced by Hofstede (1980), and we attempt to provide answers to the following two questions:

How do cultural differences affect the student-teacher interactions in the classroom, when the student and the teacher are from different cultures?

How can the conflicts be resolved to create effective learning environments?

\section{Cultural Conflicts and Resolutions - US Teacher vs. Arabian Student}

Hofstede's (1980) index values for the four cultural dimensions in the US, Arabia and France are given in Table 1. Figure 2 provides a graphical interpretation of the differences in cultural dimensions and the potential conflicts between the US and the Arabian cultures, based on the index values in Table 1. The US ranks lower than Arabia in the dimensions of Power Distance and Uncertainty Avoidance, and higher in the dimensions of Individualism vs. Collectivism, and in Masculinity vs. Femininity. Obviously this can lead to conflicts for a US teacher in a classroom with students from Arabia.

Table 1: Index of Cultural Dimensions - US, Arabia, and France

\begin{tabular}{|c|c|c|c|}
\hline $\begin{array}{l}\text { Index of Cultural Dimensions } \\
\text { (Mean Index Value for all dimensions 53) }\end{array}$ & US & Arabia & France \\
\hline $\begin{array}{l}\text { Power Distance Index } \\
\text { (PDI) }\end{array}$ & 40 & 80 & 68 \\
\hline $\begin{array}{l}\text { Uncertainty Avoidance Index } \\
\text { (UAI) }\end{array}$ & 46 & 68 & 86 \\
\hline $\begin{array}{l}\text { Individualism / Collectivism Index } \\
\text { (I / C) }\end{array}$ & 91 & 38 & 71 \\
\hline $\begin{array}{l}\text { Masculinity / Femininity Index } \\
(\mathrm{M} / \mathrm{F})\end{array}$ & 62 & 53 & 62 \\
\hline
\end{tabular}

For example, the US teacher can be non-hierarchical, preferring open, two-way communications and discussions. Discourses and debates are expected in transferring knowledge, and the teacher is willing and able to say "I don't know" to questions from students. The pedagogy is student-centered, with students treated as equals in the process of "learning to learn". The students are expected to be assertive and competitive. Individual initiative and excellence are encouraged, but, students are also required to interact well with peers and in groups. Truth is relative (rather than absolute), and the focus is more on material rewards than spiritual connections. Successful, individual performance is the ultimate goal, leading to both social respect and economic success. 
Figure 2

Hofstede's Cultural Dimensions for a US Teacher and an Arabian Student

\section{Cultural Conflicts - US Educator vs. Arabian Student}

The graphs are based on the indices of cultural dimensions for the US and Arab countries developed by Hofstede (1980)
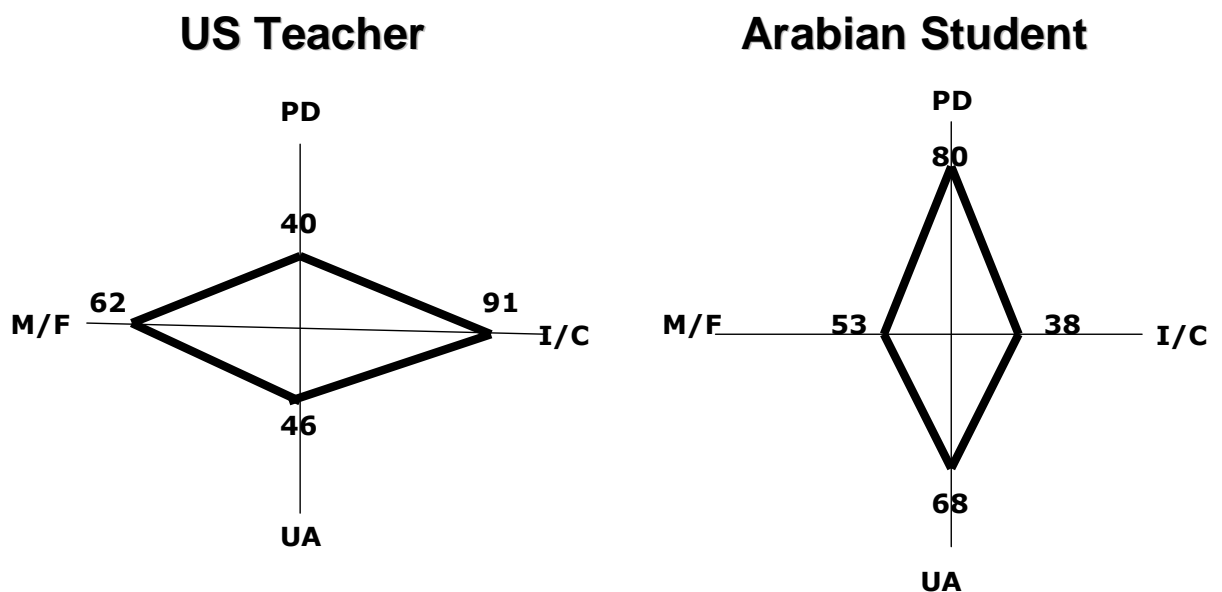

PD=Power Distance; M/F=Masculinity/Femininity; I/C=Individualism/Collectivism; UA=Uncertainty Avoidance

On the other hand, the Arabian students may place the teacher on a pedestal, believing the teacher to be "the expert" and "the guru", who is then expected to impart the wisdom in a structured environment. The expectation is for a teacher-centered pedagogy in a top-down communication framework. The quality of learning is directly linked to the excellence of the teacher, who is expected to inspire with the absolute truth. The students can be non-aggressive, non-competitive, and non-vocal, preferring group harmony over individual achievement. Ethnocentric group behaviors (such as saving face vs. shaming) may be the norm, with students focusing on self-esteem, friendliness and social adaptation. Of course, success is preferred to failure, but the goal is "learning to do" rather than "learning to learn" and diplomas are viewed as leading to a higher social status than being essential for career success.

In such a cross-cultural environment, the expectations of the teacher and the students are at odds with each other both in terms of what should be taught / learnt and how it should be done. Creating an effective and efficient learning environment now becomes the responsibility of the teacher. We believe that the educator needs to focus on the students' cultural dimensions and design a pedagogy that provides a safe and comfortable setting for the students to succeed. In this particular case of dealing with Arabian students, the teacher has to create a more structured, hierarchical and teacher-centered classroom. The teacher should also value the preference of the students to be members of the group, while encouraging individual interaction and participation in a non-threatening manner. It may also be a useful strategy to make the students aware of the cultural differences in a global framework, as this will allow the teacher to introduce non-traditional but valuable learning tools to the students, as part of the discovery process. Anecdotal evidence indeed confirms the success of such strategies. 


\section{Cultural Conflicts and Resolutions - US Teacher vs. French Student}

The cultural dimensions of France as a nation offer interesting comparisons with both the US and Arabia. As can be seen in Table 1 and Figure 3, the French are similar to the Arabians in exhibiting high index values for Power Distance and Uncertainty Avoidance; but, they are similar to Americans with high or higher index values for Individualism / Collectivism and Masculinity / Femininity. This obviously translates into values, beliefs, characteristics and expectations similar to Arabian students on some dimensions, but also analogous to the American teacher on the others.

Figure 3

Hofstede's Cultural Dimensions for a US Teacher and a French Student

\section{Cultural Conflicts - US Educator vs. French Student}

The graphs are based on the indices of cultural dimensions for the US and France developed by Hofstede (1980)

US Teacher

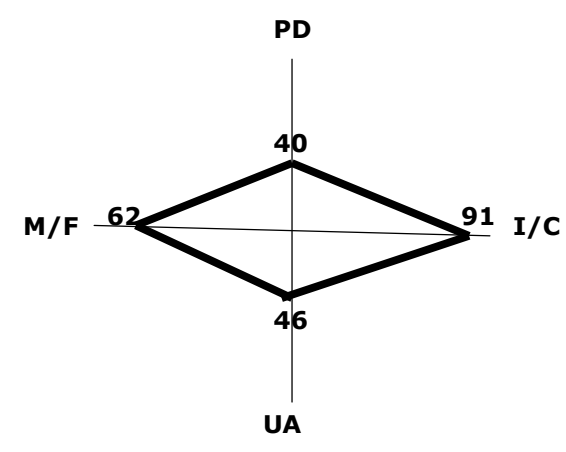

French Student

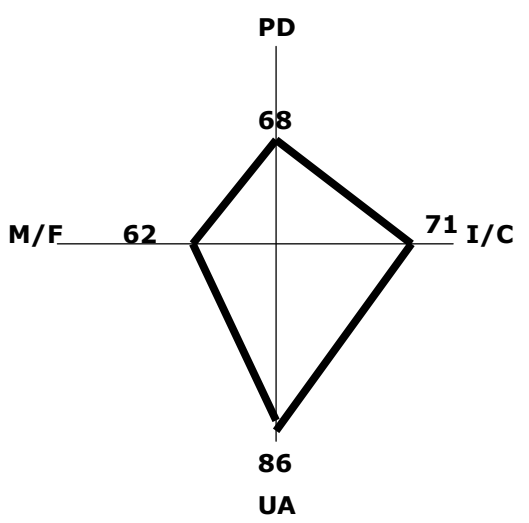

PD=Power Distance; M/F=Masculinity/Femininity; I/C=Individualism/Collectivism; UA= Uncertainty Avoidance

For example, similar to the Arabian students, French students also believe in and defer to the personal wisdom and academic excellence of the teacher. In addition, they also expect the teacher-scholar to have all the right answers and endow them with the absolute truth, in a top-down, structured setting. On an individual level failure is unacceptable. But, contrary to the Arabian students, the French students value teacher-initiated discourse and debate as well as individual success and recognition. While they may not contradict the teacher, they enjoy interactive discussions in the classroom. Both brilliance and friendliness in the teacher are expected and appreciated and students are interested in and appreciate the intrinsic value of knowledge and scholarship. They can also be assertive, aggressive, competitive, and individualistic, all of which are cherished values in the US culture.

The strategies for successful pedagogy in this case will have the US teacher providing a structured learning environment, while encouraging active engagement through debate and discourse from the students. The educator will also have to demonstrate that students are valued for their individual initiatives as well as for their contributions to intellectual discourse. But, in the end the teacher has to establish and exhibit his/her intellectual superiority, in order to win the respect of the students. 
Globally successful teachers recognize the vital need to be in tune with potential conflicts in cross-cultural teaching and learning environments, and adopt appropriate strategies to create a pedagogical framework that is effective and enjoyable, both to the educator and the student. This will be increasingly relevant in the $21^{\text {st }}$ century and beyond, as the world and its nations/cultures become more actively engaged with each other and cross-cultural interactions increase across the entire economic spectrum.

\section{CONCLUSIONS AND RECOMMENDATIONS FOR FURTHER RESEARCH}

A nation's culture often defines not only an individual's identity, but also the collective values, beliefs, attitudes, and even the symbols, practices and rituals. Hofstede's $(1980,2001)$ pivotal and influential works on cultural dimensions, provide the framework for understanding the cultural differences among peoples of different nations. In doing this research, we hypothesize that culture and its dimensions have an influence on the students, the teachers, and the student / teacher interaction, and propose an integrated framework in an effort to provide tools for developing globally competent business educators. We develop a framework based on the index values of the four cultural dimensions (power distance, uncertainty avoidance, individualism/collectivism and masculinity/femininity) to identify the characteristics of a typical US teacher and quintessential Arabian and French students. These differential dimensions, by their very nature, contribute to potential conflicts in a cross-cultural teaching/learning environment, with the educator and the students coming together albeit with different values systems and resulting expectations. It is then the responsibility of the teacher to understand (and enunciate to the students, if necessary) the implications thereof and devise innovative pedagogical frameworks to succeed as a globally competent teacher.

We provide some suggestions for the US educator in dealing with Arabian and French students. Of course, this is a first step in understanding and analyzing a complex area, and leaves several areas ripe for further research. The index-based framework for understanding the impact of cultural dimensions on teachers and students has been a valuable exercise, but one that relies purely on theory, observation, intuition and anecdotes. While it provides insights into the potential conflicts in cross-cultural pedagogy, its validity has to be established by further empirical research. In addition, we have only delineated two specific cross-cultural comparisons - US teacher vs. Arabian student and US teacher vs. French student. Needless to say that many more such comparisons need to made and validated in the future.

In addition, we have implicitly assumed that all teachers and all students within any given culture will have similar characteristics in terms of their teaching and learning, respectively. But, it is possible that within each culture teachers will have different teaching styles and students will prefer different learning styles. Each of these may in turn correlate with varying levels of index values for the cultural dimensions of Hofstede (1980). This then leads to the need to understand the cultural dimensions implicit in each teaching/learning style, and identify the potential conflicts not just in terms of the cultural dimensions, but also in terms of teaching and learning styles. As more and more educators and educational institutions venture deeper and farther into providing international exposure and experience to their students, this stream of research also becomes vitally important to create an environment that leads to success in such endeavors!

\section{REFERENCES}

1. Badley, G. (2000). Developing Globally-Competent University Teachers, Innovations in Education and Training International, IETI, Volume 37, Issue 3. Online at http://www.tandf.co.uk/journals.

2. Garson, B. (2005). Teaching Abroad: A Cross-Cultural Journey, The Journal of Education for Business, July/August.

3. George, P., (1995). College Teaching Abroad: A Handbook for Strategies for Successful Cross Cultural Exchanges, Allyn \& Bacon Publishers.

4. Gibb, A. A., (1996). Entrepreneurship and Small Business Management: Can we Afford to Neglect them in the Twenty-First Century Business School? British Journal of Management, Volume 7, Number 4.

5. Hall, D. E. (2007). Why Professors Should Teach Abroad? Chronicle of Higher Education, Volume 54, Issue 6.

6. Hofstede, G. (1980). Culture's Consequences: International Differences in Work-Related Values. Newbury Park, California, USA: Sage. 
7. Hofstede, G. (1986). Cultural Differences in Teaching and Learning, International Journal of Intercultural Relations, Volume 10.

8. Hofstede, G. (1991). Cultures and organizations: Software of the mind. London: McGraw-Hill.

9. Hofstede, G. (2001). Culture's Consequences, $2^{\text {nd }}$ edition, Sage Publications.

10. Manikutty, S., Anuradha, N.S., and Hansen, Katrin. (2007). Does culture influence learning styles in higher education? International Journal of Learning and Change, Volume 2, Number 1.

11. Richards, N., Ross, D. L. (2004). Offshore teaching and learning: an exploratory Singaporean study, The International Journal of Educational Management, Volume 18, Issue 4/5.

12. Richardson, J. T. E. (1994). Cultural Specificity of Approaches to Studying in Higher education: A Literature Survey, Volume 27, Number 4.

13. Ramburuth, P. (2000). Cross Cultural Learning Behaviour in Higher Education: Perspective versus Practice, Seventh International Literacy and Education Research Network Conference on Learning, RMIT University, Melbourne.

14. Seah, W.T., and Edwards, J. (2006). Flying In, Flying Out: Offshore Teaching in Higher Education, Journal of Education, Vol. 50, No. 3, 297-311

15. Spencer-Oatey, H. (1997). Unequal relationships in high and low power distance societies: A comparative study of tutor-student role relations in Britain and China, Journal of Cross-Cultural Psychology, Volume 28.

16. Stroebe, W. (1976). Is social psychology really that complicated? A review of Martin Irle's Lehrbuch der Sozialpsychologie,. European Journal of Social Psychology, Volume 6.

17. Vunderink, M and Hofstede, G. (1998). Femininity shock: American Students in the Netherlands. In G. Hofstede \& Associates, Masculinity and Femininity: The taboo dimension of national cultures. Thousand Oaks, CA: Sage. 